\title{
Kinetic study on removal of heavy metal ions from aqueous solution by using soil
}

\author{
Soh-Fong Lim • Agnes Yung Weng Lee
}

Received: 13 August 2014 / Accepted: 3 February 2015 / Published online: 19 February 2015

(C) Springer-Verlag Berlin Heidelberg 2015

\begin{abstract}
In the present study, the feasibility of soil used as a low-cost adsorbent for the removal of $\mathrm{Cu}^{2+}, \mathrm{Zn}^{2+}$, and $\mathrm{Pb}^{2+}$ ions from aqueous solution was investigated. The kinetics for adsorption of the heavy metal ions from aqueous solution by soil was examined under batch mode. The influence of the contact time and initial concentration for the adsorption process at $\mathrm{pH}$ of 4.5 , under a constant room temperature of $25 \pm$ $1{ }^{\circ} \mathrm{C}$ were studied. The adsorption capacity of the three heavy metal ions from aqueous solution was decreased in order of $\mathrm{Pb}^{2+}>\mathrm{Cu}^{2+}>\mathrm{Zn}^{2+}$. The soil was characterized by Fourier transform infrared (FTIR) spectroscopy, scanning electron microscopic-energy dispersive X-ray (SEM-EDX), and Brunauer, Emmett, and Teller (BET) surface area analyzer. From the FTIR analysis, the experimental data was corresponded to the peak changes of the spectra obtained before and after adsorption process. Studies on SEM-EDX showed distinct adsorption of the heavy metal ions and the mineral composition in the study areas were determined to be silica $\left(\mathrm{SiO}_{2}\right)$, alumina $\left(\mathrm{Al}_{2} \mathrm{O}_{3}\right)$, and iron(III) oxide $\left(\mathrm{FeO}_{3}\right)$. A distinct decrease of the specific surface area and total pore volumes of the soil after adsorption was found from the BET analysis. The experimental results obtained were analyzed using four adsorption kinetic models, namely pseudofirst-order, pseudo-second-order, Elovich, and intraparticle diffusion. Evaluating the linear correlation coefficients, the kinetic studies showed that pseudo-second-order equation described the data appropriable than others. It was concluded
\end{abstract}

Responsible editor: Zhihong $\mathrm{Xu}$

S.-F. $\operatorname{Lim}(\bowtie) \cdot$ A. Y. W. Lee

Department of Chemical Engineering and Energy Sustainability, Universiti Malaysia Sarawak, Kota Samarahan 94300, Malaysia e-mail: sflim@feng.unimas.my

S.-. Lim

e-mail: sflim@alumni.nus.edu.sg that soil can be used as an effective adsorbent for removing $\mathrm{Cu}^{2+}, \mathrm{Zn}^{2+}$, and $\mathrm{Pb}^{2+}$ ions from aqueous solution.

Keywords Adsorption · Heavy metal ions · Soil $\cdot$ Kinetic models

\section{Introduction}

The problems of the ecosystem are growing with developing technology and heavy metal pollution is one of the main problematic issues (Uzun and Güzel 2000). The widespread existence of heavy metal in water environment either from natural or anthropogenic sources, has deposited considerable public and political discussion relating to potential impacts on human health and wildlife as well as aquatic habitats (Orisakwe et al. 2012).

Prolonged exposure to heavy metals such as cadmium, copper, lead, nickel, and also zinc can cause deleterious health effects in humans (Singh et al. 2011). Significant worldwide research efforts are stimulated toward developing methods for heavy metal removal from drinking water due to the heightened awareness of the toxicity and regulatory modification (Tilson 2013).

Each of the current technologies has its own merits and demerits besides playing an important role in preventing widespread heavy metal toxicity in nature. Adsorption has been widely used for purification, separation, and compliance purposes in many industries at large scales (Shah et al. 2013). The fact that adsorption can be used with liquid process stream with high efficiency, low cost, and friendly operating conditions have made it a usual process in various industries is undeniable. Activated carbons (ACs), polymeric adsorbents, and zeolites are the main categories of adsorbents used to 